\title{
CONCERN ABOUT FAIRNESS, ETHICAL IDEALISM AND DEMAND FOR INFORMATION SYSTEMS AUDIT IN ORGANIZATIONS
}

\author{
Joseph S. Mollick, Texas A\&M University - Corpus Christi, joseph.mollick@tamucc.edu
}

\begin{abstract}
Customers are concerned about the fairness of information management in organizations. What do concerned customers want information-intensive organizations to do to mitigate their concerns? How does customers' ethical idealism affect what customers want organizations to do to protect customers' information privacy and related rights? Using data collected from a sample of 208 customers of a large organization, we investigate the effects of concern about fairness and ethical idealism on customers' demand that organizations adopt a policy of conducting periodic information systems audits. We find that customers' concern about fairness of organizational information management practices and customers' level of ethical idealism positively correlate with customers' demand that organizations adopt a policy of conducting periodic information systems audits. Implications of the discovery of these positive relationships are discussed in light of ethics, strategy, design, control and administration of personal information management systems in information-intensive organizations.
\end{abstract}

Keyword: Information Systems Audit, Ethical Idealism, Fair Information Management Practices, Universities, Students.

\section{INTRODUCTION}

Individuals and organizations and their interactions continue to be increasingly dependent on data, databases, and computer networks that facilitate exchanges, transactions and interactions of all kinds. Data collected from transactions and exchanges among different stakeholders of an organization serve as the raw material for the practice of data science, business analytics, data mining and business intelligence for managers. As organizations computerize their information intensive processes, ethical tensions between organizations and individuals affected by organizational practices related to the management of personal data gain heightened importance. For example, customers worry if data about customers are being used by organizations to unfairly exploit customers. Individuals' concern about fairness of information management (X1) in organizations [26] has been identified as one of the important considerations facing knowledge workers ranging from law enforcement officers to e-commerce managers and database administrators responsible for managing organizational information resources. Since it is common for information technologists to be more process oriented than people-oriented, it is important to note that emphasis on process over what customers want has been identified as a concern that can be responsible for failure of programs such as customer relationship management programs and database marketing programs. As organizations become more information-based [4], concerns related to fairness of information management becomes a more relevant factor for keeping the information management functions of organizations customer-centered. This concern is stronger among individuals who are ethically idealistic. Concern about fairness of information management can lead consumers such as students of a university to demand that universities put in place formal procedures, such as a policy of performing periodic information systems audits, to protect students from harm. The dependent variable in this study is students' demand that universities put in place a policy of performing periodic information systems audits (Y).The research question we ask is: do concern about fairness of information management and individuals' ethical idealism positively correlate with customers' demand that administrators put in place a policy of performing periodic IS audits in organizations? The question asked in this study is timely and can be relevant to managers of information intensive organizations such as universities and hospitals.

\section{LITERATURE REVIEW}

It is important to show continuity of the current study with prior studies $[16,17,18,19,20,21]$ related to the relationships among the two independent variables and the dependent variable in this study. 
Concern about Fairness of Information Management by Organizations (X1)

It has been reported by information ethics scholars $[11,9,12]$ that individuals worry about how fair, just and balanced organizations are in managing competing interests among different stakeholders of information collected, stored and managed by organizations. Individuals' concern about fairness can be understood, according to Rawls [23], as a concern for justice which is considered by many as the highest order ethical principle. A just order of things allows each to play a proper role in society. The use of information and communications technologies, both old and new, by organizations and individuals, warrants a continuous examination and re-examination of different stakeholders' concerns about fairness of information management practices and their demands or expectations of possible safeguards and remedies. For example, concerns about the fair use of radio-frequency identification (RFID) by organizations are relatively new but relevant issues for individuals and organizations. Under what circumstances is it fair to use an RFID tag for the purpose of identification and tracking objects, animals or persons? On the other hand, concerns about fairness of the methods and procedures of archiving, updating and disposing of data, access control mechanisms, balanced reporting and fair use of personal information stored in databases are over forty years old but still relevant issues. How concerned individual members of an organization feel about the fairness of an organization's information management activities need to be continuously measured and monitored by managers and policy makers because customers' fears and concerns about fairness can have negative consequences for relationships between organizations and their members.

Individuals' concern about fairness of information management practices in organizations has antecedents and consequences. Identification of antecedents of concern about fairness can be helpful for understanding the factors that positively or negatively affect individuals' feeling of concern about fairness of information management in organizations. Knowledge of consequences of individuals' concern about fairness of information management can help managers and policy makers realize what outcome variables may be attributed to individuals' concern about fairness of organizational information management practices. Knowledge in this domain can help organization designers and managers design effective intervention strategies to prevent or reduce undesirable outcomes and to help an organization succeed in achieving justifiably desirable goals. Because of this practical importance for goal seeking entities in societies, a huge volume of research studies have been and continue to be conducted with the sole purpose of understanding the antecedents and consequences of individuals' concern about fairness of different organizational practices. Many of these practices are not much related to the domain of information management activities - but about organizational practices in other areas such as marketing and advertising, hiring and firing practices, incentive systems and the like.

Individuals demand that an organization effectively respond to individual stakeholders' concern about fairness of organizational practices related to information management [11]. Database experts such as Date [3] have been warning about safeguards that must be built in the design and administration of databases so that confidentiality, integrity, access rights and privileges, and information privacy can be managed within principles of justice and fairness. Legal scholars like Miller [13] have written about the legal responsibilities of organizations and individuals to protect the privacy of data stored in computer databases. These writings and reports in popular news media about unfair uses of personal information are antecedents of an individuals' concern about fairness of information management by organizations. Mollick [16] finds that students' concerns about use of data for personal profiling and their concern about fairness of organizational information management are positively related to students' feeling of alienation from a university. It can be argued that concern about fairness is a reason for Mollick and Pearson [21] to find that students' concern about collection and uses of personal data lead to their feeling of alienation from a university. Why do concern about error in data and access to data lead students to feel alienated from a university [14] It can be argued that students perceive organizational practices related to management of error control and access control mechanisms as inadequate to the point of being unfair and this perception of unfairness of organizational practices lead them to feel alienated. It is important for organizations to understand the antecedents and consequences of customers' concern about fairness of organizational practices.

\section{Individuals' Ethical Idealism (X2)}

Individuals differ in their ethical ideologies. Ideological orientations or tendencies influence human beings in how they form ideals. Ideals are important because they have the capacity to guide thought and action. Social psychologists and ethics scholars such as Forsyth $[5,6]$ have studied and continue to study the effects of ethical ideology on individuals' evaluation of action and moral behavior. It has been reported in these studies that 
individuals' moral judgments of certain business practices and their decisions to engage in those practices are influenced by their personal moral philosophies or ideologies. There can be as many personal moral philosophies as there are persons. However, two broad classifications of personal moral philosophies are moral relativism and idealism. Idealists are sometimes called absolutists. Absolutists or idealists assume that actions are moral, provided they yield positive consequences and conform to moral rules or principles. In this paper an individual's ethical idealism has been defined as one's level of idealistic orientation in ethical philosophy which is based on fixed, categorical principles, and does not change according to circumstances. Principles of ethics or moral rights and wrongs, according to ethical idealism, are absolutes--they do not depend on the context or circumstances of a situation.

How do judgments, behavioral choices and demands for organizational action differ along an individual's level of moral idealism? An answer to this question can be useful for managers of organizations. The different stakeholders of an organization would be interested to know and judge the legality and ethics of policies and practices implemented by managers. To different degrees, unethical organizational actions can be very harmful for some or all of the stakeholders of an organization. If managers can properly understand how evaluations or judgments and actions of different stakeholders of an organization are influenced by their level of ethical idealism, they can better respond to ethics related demands of different stakeholders such as customers. Mollick [18] finds that ethical idealism is positively related to individuals' demand for notice about uses of personal information by organizations. The discussion of ethical idealism in this paper is similar to the notion of ethical idealism discussed in Mollick [18].

\section{Demand for Information Systems Audit (Y)}

In the context of a university as the organization and students as its customers, the dependent variable, demand for information systems audit, measures the extent to which a student believes that information management activities of a university should be periodically audited for adherence to relevant laws, organizational policies and procedures of information management. Students may believe that auditing can be a remedy to problems related to errors and ethics of information management at universities. The dependent variable indicates the extent of one's support for a policy of authorizing audit of information management functions at universities. Demand for a policy of IS audit is expressed as an individual's support that a methodical examination and review of an activity will be a remedy to the problems of error and ethics related to that activity. Administrative units such as admissions and records, along with the financial aid office of a university, should be interested in learning more about students' support for a policy of carrying out periodic IS audit. Students may view an IS audit policy as a remedy to problems and as a proactive gesture of good will because it may solve some of the information ethics problems seen in data management activities. To measure this construct, two statements about demand for IS audit were presented to respondents who provided their level of agreement with the statements (see Appendix A).

Demand for IS audit can be conceptualized as a construct related to demand for formal procedures of information management [15] because adopting and implementing a policy of IS audit in an organization is part of the process of formalization of the procedures of the information management function. Students' demand for a university to put in place formal procedures, such as IS audit, in managing information about students can be viewed in the context of the relationship between an organization and customers who have been internalized [27] by their organization. Customers' demand for implementation of formal procedures in the organizational information management function can be viewed in light of the structural contingency theory [27] that claims that faced with risk and uncertainty, an organization attempts to reduce risk and uncertainty through formal structures and bringing uncertain external elements under control of formal structure of the organization. By specifying in written documents procedures, methods and steps that must be followed in each step of the organizational data management function which include collection, storage, updating, and disposing of data, an organization can bring structure to what was previously unstructured and therefore uncertain, risky and prone to error, neglect and abuse.

Mahmood and Becker [10] found a significant predictive relationship between Nolan's (1973) organizational maturity variables and satisfaction of information systems end-users. Demand for formal procedures can also be viewed in light of organizational maturation $[22,10]$ theory which claims that the more the information management function matures in organizations, the more formal end-users may expect its management procedures to become. Formal procedures, such as adoption and implementation of periodic IS audit, can be viewed as helpful for the 
development and maintenance of trust in a system because formalization makes it more routine and predictable and less uncertain. To protect themselves from the harmful effects of irresponsible information management, students will want formal procedures like IS audit to prevent unfair uses of data about them. Formal procedures may include that procedures and methods of archiving, updating and disposing of data be clearly and adequately specified in writing. It may include the provision that each person in charge of updating data be adequately identified by a signature or mark so that a complete audit trail can be established and accountability can be established. Demand for formal procedures includes the demand that each step of data processing be documented and recorded so that an audit trail is maintained. As part of formal procedures, periodic monitoring activities, such as IS audits, need to be carried out to check that the university is complying with information-oriented laws [12].

We have chosen to study the correlation between concern about fairness in data management, individuals' ethical idealism and demand for IS audit of information management in the context of a relationship between students and their university because of the information-intensive nature of the exchanges and processes that define these individual-organization relationships. Drucker [4] predicted that organizations of the future would become increasingly information-based such as hospitals and universities. Organizations such as universities are expected to be conscience-carriers [12] and moral agents in how they use information-power over different stakeholders [25]. Sources of power include information-based organizations' ability to collect, access, store, possess, legally own, control, share, communicate and buy or sell information about different stakeholders. Organizations are networks among individuals within and around an invisible legal entity. As such, organizations are often more powerful than individuals. Different scattered individual stakeholders of the organization can be subjected to indignity, injustice and harm because of what powerful information-based organizations do or fail to do with regard to ensuring the fairness of information management procedures. In light of the research model stated in Figure 1, we theorize below that as organizational processes become more information-intensive, a sense of concern about fairness of information management increases, and so does individuals' demand for formal procedures, such as IS audits, to govern the organizational information management function.

In the context of an existing relationship between an organization and its internalized customers, members have a sense of belonging [1], membership [24] and mutual dependency. Internalized customers who carry out their transactions with their organization in the context of a reciprocal relationship operate on the basis of an expectation of good faith that their organization will be ethical, trustworthy, procedurally fair and just and responsible in how it manages their personal information. Adoption and implementation of a policy of periodic IS audits can help maintain good faith and trust necessary for maintaining reciprocally beneficial relationships between organizations and their customers.

\section{RESEARCH MODEL AND HYPOTHESES}

\section{The Research Model}

A large U.S. university represents what Drucker [4] would call an 'information-based' organization, and students would represent customers of that information-based organization. As presented in the research model in Figure 1, we attempt to theorize and empirically test the effects of two independent variables - students' concern about fairness of information management $\left(\mathrm{X}_{1}\right)$, and individuals' ethical idealism $\left(\mathrm{X}_{2}\right)$ —on students' demand for adoption and implementation of a policy of periodic IS audit (Y). In light of the literature review above, a research model is presented in Figure 1.

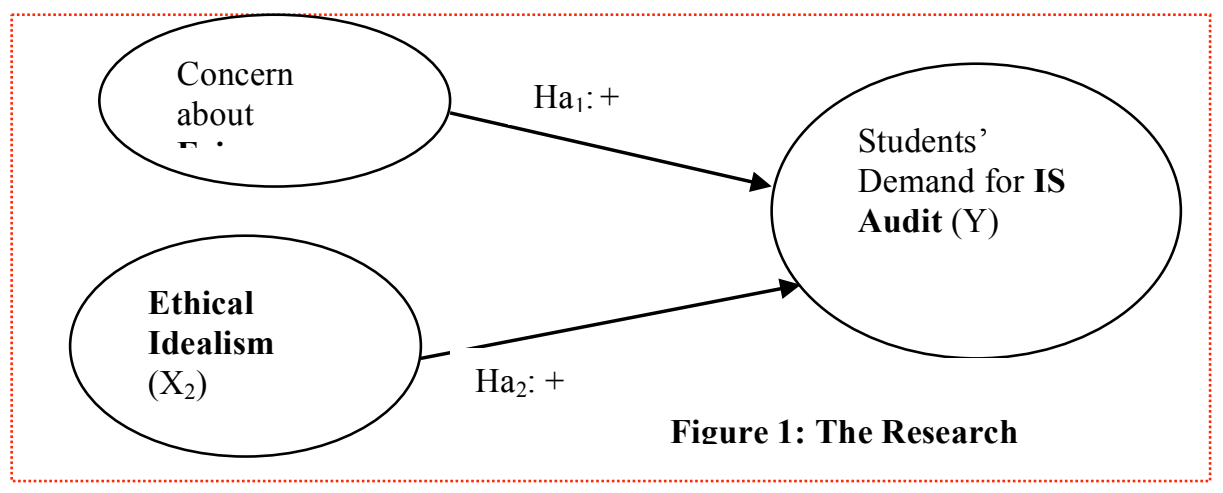


The current study extends existing knowledge in that it theorizes and tests how concern about fairness of information management $\left(\mathrm{X}_{1}\right)$ and individuals' ethical idealism $\left(\mathrm{X}_{2}\right)$ are related to students' demand that universities put in place formal procedures to govern the information management function $(\mathrm{Y})$.

\section{Research Hypotheses: Ha1 and Ha2}

As shown in Figure 1, two research hypotheses are developed. Hypotheses Ha1 and Ha2 are about the main effects of $\mathrm{X} 1$ and $\mathrm{X} 2$, respectively, on the dependent variable $\mathrm{Y}$. In a multiple regression model specified as $\mathrm{Y}=$ $\beta 0+\beta 1 * X 1+\beta 2 * X 2$, the research model hypothesizes that both beta coefficients, if estimated based on data collected from a sample, will be positive. Explanations and arguments to support Ha1 and Ha2 are presented below.

\section{Ha1: Concern about Fairness (X1) and Demand for IS Audit (Y)}

What could be some of the consequences of customers' concern about organizational fairness in the domain of information management? In light of equity theory and theories of justice, it can be said that concern about fairness will lead to a feeling of alienation [16], a lower motivation to belong to an organization [1] and a lower motivation to cooperate. For example, when asked to fill up a form or participate in a survey, customers may not volunteer to cooperate. If coerced or forced to cooperation with an organization that they perceive is unfair, concern about fairness may even lead members to protest, bring law suits or participate in a violent revolt against the organization or institution that is held responsible for unfairly handling information about customers. However, if customers want to continue to belong to an organization and cooperate with an organization even as they feel that the organization is not being fair in information management procedures, they will demand that the organization be responsive to their fears and concerns and stop alienating customers by implementing formal procedures of information management that will address their concern about fairness of information management. One such formal procedure that can help ensure fairness, and reduce errors, abuses and violations of individuals information privacy rights can be adoption and implementation of a policy of periodic IS audit in an organization. Simply put, customers will demand a formal procedure, such as IS audits, to be in place with the hope that the more formal the procedures are for information management functions, the more customer-centric [19] and fair they will be. A policy of performing periodic information systems audits can be viewed as one of the formal procedures of information management in organizations.

Research Question $\left(\mathrm{RQ}_{\mathrm{i}}\right)$ and Hypothesis $\left(\mathrm{H}_{\mathrm{i}}\right)$

The discussions presented this far can be formally summarized in the form of a research question and a related hypothesis about the relationship between $\mathrm{X} 1$ and $\mathrm{Y}$.

$\mathrm{RQ}_{1}$ : Do customers' level of concern about fairness of information management positively correlate with customers' demand that the organization put in place formal procedures in the management of its information about customers? $\mathrm{Ha}_{1}$ : The higher individuals' concern about fairness of information management $\left(\mathrm{X}_{1}\right)$, the higher their demand that the organization put in place formal procedures in the management of its information about customers. It is hypothesized that there is a positive correlation between $\mathrm{X}_{1}$ and $\mathrm{Y} . B_{1}>0$ in the model $\mathrm{Y}=\beta \mathrm{o}+\beta 1 * \mathrm{X} 1+\beta 2 * \mathrm{X} 2+$ $\beta 3(\mathrm{X} 1 * \mathrm{X} 2)$. Using correlation coefficient $\mathrm{r}$ between $\mathrm{X} 1$ and $\mathrm{Y}$, research hypothesis Ha1 can be stated as $\mathrm{r}_{\mathrm{x} 1 \mathrm{y}}>0$.

\section{Ha2: Ethical Idealism (X2) and Demand for IS Audit (Y)}

The second research hypothesis is that $\mathrm{X} 2$ and $\mathrm{Y}$ are positively related. It means the more idealistic an individual is in ethical orientation, the more strongly an individual believes that an organization should put in place a policy of adopting and implementing information systems audit in the management of information collected and stored in organizations. Different organizations like schools and universities would be interested in learning about the relationship claimed in $\mathrm{Ha} 2$. One argument to support $\mathrm{Ha} 2$ is that implementation of an IS audit policy will be perceived by students as a fair procedure (Greenberg, 1990) of information management. Another argument to support Ha2 is that the policy of implementing IS audit will be perceived as a practice that reduces uncertainty, asymmetry, and probability of errors, abuses and violations in how information is managed by an organization. As sunlight takes away the mystery of darkness that may scare many people, so does an IS audit policy bring some 
certainty, structure and possibly transparency in an organization's information practices. Transparency and lack of asymmetry can reduce individuals' fear and leave them with less anxiety and more feeling of peace, certainty and security. Since idealistic orientation of individuals is associated with demand for responsibility, accountability and adherence to a code of ethics $[28,29]$, the more idealistic one is in moral philosophy the more strongly one will demand transparency and demand that formal procedures such as IS audit of information management be implemented in an organization. These arguments support $\mathrm{Ha} 2$ as formally stated below.

Research Question $\left(\mathrm{RQ}_{\mathrm{i}}\right)$ and Hypothesis $\left(\mathrm{H}_{\mathrm{i}}\right)$

The discussions presented this far can be formally summarized in the form of a research question and a related hypothesis about the relationship between $\mathrm{X} 2$ and $\mathrm{Y}$.

$\mathrm{RQ}_{2}$ : Do customers' level of ethical idealism positively correlate with customers' demand that the organization put in place a policy of adopting and implementing information systems audit in the management of information collected and stored in organizations?

$\mathrm{Ha}_{2}$ : The higher individuals' ethical idealism $\left(\mathrm{X}_{2}\right)$, the more they demand that the organization put place a policy of adopting and implementing information systems audit in the management of information collected and stored in organizations. It is hypothesized that there is a positive correlation between $\mathrm{X}_{2}$ and $\mathrm{Y} . B_{2}>0$ in the model $\mathrm{Y}=$ $\beta \mathrm{o}+\beta 1 * \mathrm{X} 1+\beta 2 * \mathrm{X} 2+\beta 3(\mathrm{X} 1 * \mathrm{X} 2)$. Using correlation coefficient $\mathrm{r}$ between $\mathrm{X} 2$ and $\mathrm{Y}$, research hypothesis $\mathrm{Ha} 2$ can be stated as $\mathrm{r}_{\mathrm{x} 2 \mathrm{y}}>0$.

\section{Sample}

\section{METHOD}

The researcher solicited 241 students at two US universities to answer an online questionnaire. Students were promised extra credit points in exchange for participation. Two hundred and eight students completed the survey. Because of a high response rate of over $86 \%$, non-response bias, if any existed, would not be high. Of the 208 students, 58 were graduate business students and 150 were undergraduate business students, 108 were men and 100 were women. Statistical tests indicated no significant differences between graduate and undergraduate or male and female students' scores on the X1, X2 and Y variables under study. Because the survey was set up online in a way that did not allow respondents to submit the survey without answering all the questions, there were no instances of missing data. The percentage of male students was approximately $52 \%$ and female students made up $48 \%$ of the sample.

\section{Questionnaire}

Seven-point Likert type scales were used to measure the level of concern customers had about fairness of information management, customers' ethical idealism and customers' demand that a policy of periodic information systems audit be adopted and implemented in organizations, such as universities. The items for measuring demand information systems audit (Y) and concern about fairness (X1) have been taken from the information ethics check list in Mason et al [12]. The items for measuring individuals' ethical idealism (X2) have been adapted from Forsyth $[5,6]$. The items in the questionnaire were adapted to the context of students at US universities. These modified items are presented in Appendix A.

\section{Reliability of the Scales of Measurement}

Cronbach's alpha values [2] were computed for each of the three constructs $\mathrm{X} 1, \mathrm{X} 2$ and $\mathrm{Y}$ to assess the consistency and inter-item reliability of the multiple-item scales. Constructs $\mathrm{X} 2$ and $\mathrm{Y}$ have Cronbach's alpha values greater than .70 and the same value for $\mathrm{X} 1$ is above .60. The generally agreed upon lower limit for Cronbach's alpha is .70 [8]. However, the acceptable lower limit may decrease to .60 for exploratory research. Inter-item reliability coefficient .801 for the 10 items used to measure ethical idealism is very satisfactory. Reliability of the construct X1, concern about fairness of information management, is acceptable based on the rationale that the construct is exploratory rather than confirmatory. 


\section{RESULTS}

The descriptive statistics and correlation matrix for $\mathrm{X}_{1}, \mathrm{X}_{2}$ and $\mathrm{Y}$ presented in Table 1 are from multi-item scales used in the survey instrument presented in Appendix A.

\begin{tabular}{|c|c|c|c|}
\hline \begin{tabular}{|c} 
Table 1: Correlation Matrix \\
and \\
Descriptive Statistics \\
\end{tabular} & $\begin{array}{c}X 1=\text { Concern } \\
\text { AboutFairness }\end{array}$ & $\begin{array}{c}X 2=\text { Ethical } \\
\text { idealism }\end{array}$ & $\begin{array}{l}Y=\text { Demand } \\
\text { For IS Audit }\end{array}$ \\
\hline $\mathrm{X} 1=$ ConcernAboutFairness & 1 & & \\
\hline $\mathrm{X} 2=$ Ethical idealism & 0.3192 & 1 & \\
\hline$Y=$ Demand For IS Audit $^{*}$ & 0.4629 & 0.3626 & 1 \\
\hline Mean & 5.61 & 5.18 & $\overline{5.67}$ \\
\hline Standard Error & 0.0546 & 0.0539 & 0.0692 \\
\hline Median & 5.7 & 5.25 & 6 \\
\hline Mode & 5.8 & 5.5 & 6 \\
\hline Standard Deviation & 0.7880 & 0.7774 & 0.9980 \\
\hline Sample Variance & 0.6210 & 0.6044 & 0.9961 \\
\hline Kurtosis & 1.1420 & -0.2866 & 0.0768 \\
\hline Skewness & -0.8370 & 0.0333 & -0.6562 \\
\hline Range & 4.6 & 4.25 & 4.5 \\
\hline Minimum & 2.4 & 2.75 & 2.5 \\
\hline Maximum & 7 & 7 & 7 \\
\hline Sum & 1167.3 & 1077.5 & 1179.5 \\
\hline Count & 208 & 208 & 208 \\
\hline Confidence Level(95.0\%) & 0.1077 & 0.1063 & 0.1364 \\
\hline
\end{tabular}

The mean score 5.67 out of 7 on Y can be interpreted as evidence that students do indeed demand that a policy of periodic information systems audit be implemented in organizations like universities to systematically address students' concerns about organizational information management practices. One-tailed t-tests on correlation coefficient $r$ between $\mathrm{X} 1$ and $\mathrm{Y}$, and correlation coefficient $\mathrm{r}$ between $\mathrm{X} 2$ and $\mathrm{Y}$ showed that both pair-wise correlation coefficients, with $p$-values less than 0.001 , were statistically significantly greater than zero. Statistically significant correlation between X1 and Y supports research hypothesis Ha1. Statistically significant correlation between X2 and Y supports research hypothesis Ha2. Based on the statistical significance test of the correlation coefficients, both research hypotheses $\mathrm{Ha} 1$ and $\mathrm{Ha} 2$ are supported with more than $99 \%$ confidence. Figure 2 has been used to visualize the positive correlation between $\mathrm{X} 1$ and $\mathrm{Y}$, which shows an initial support for research hypothesis Ha1. Figure 3 has been used to visualize the positive correlation between X2 and Y, which shows an initial support for research hypothesis Ha2.

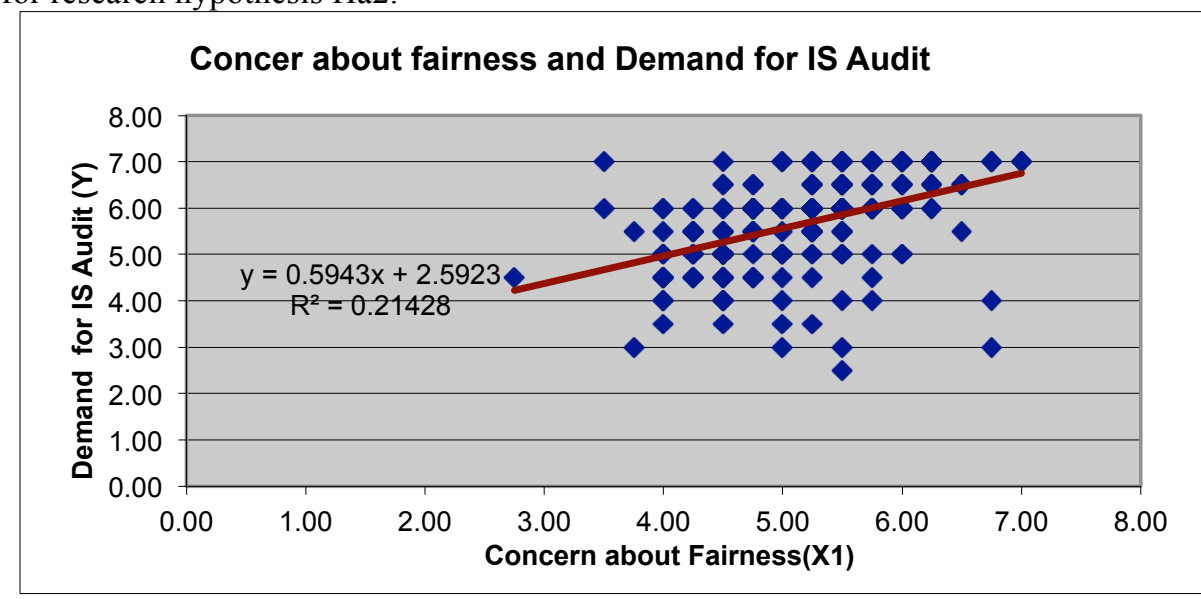

Figure 2: Correlation between $\mathrm{X} 1$ and $\mathrm{Y}$ 


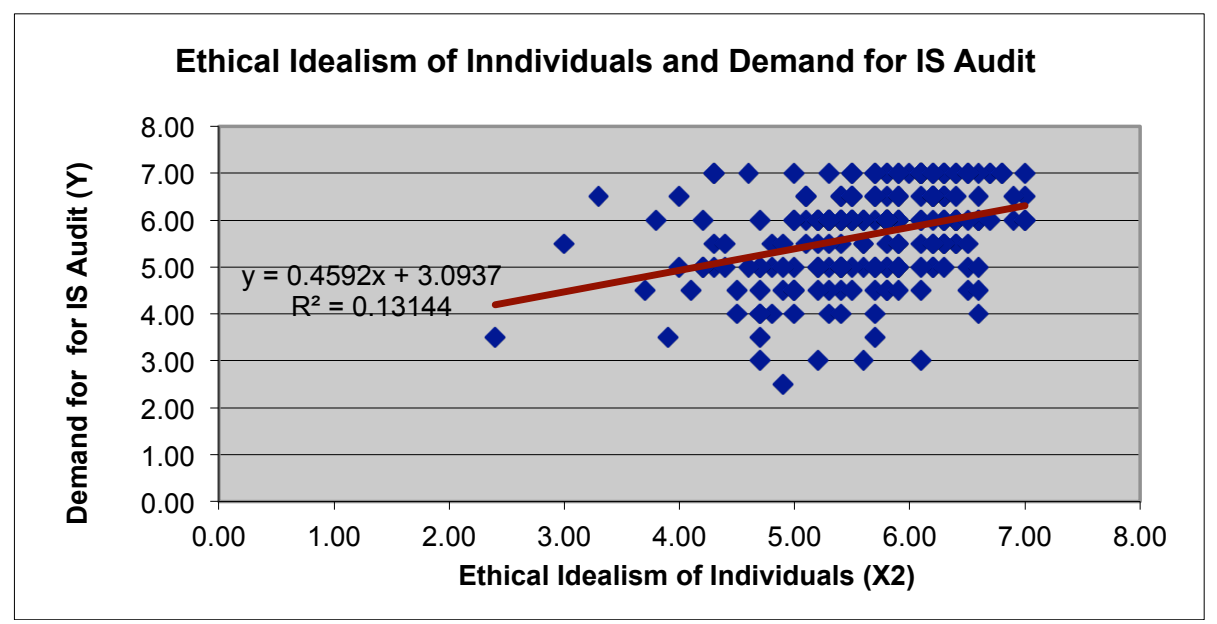

Figure 3: Correlation between $\mathrm{X} 2$ and $\mathrm{Y}$

The p-value associated with the F-test is less than .01. This indicates that the multiple regression model in which $\mathrm{X}_{1}$ and $\mathrm{X}_{2}$ have been used to predict and explain $\mathrm{Y}$ is statistically significant and useful. The one-tailed $\mathrm{p}$-value for the estimated beta coefficient for variable X1 is 0.0000 and one-tailed p-value for the estimated beta coefficient associated with the variable X2 is 0.0001 . Both p-values are less than .01, indicating with at least $99 \%$ confidence, that the sample evidence supports research hypotheses Ha1 and Ha2. As indicated by the R-Squared, the two independent variables can explain $26.57 \%$ of the variability in the dependent variable. The mean score for the dependent variable is 5.67 out of 7 and the variability in the dependent variable is relatively low, and this might help understand why the coefficient of determination is only .2657 even though the model is statistically significant.

\section{DISCUSSION, IMPLICATIONS AND FUTURE RESEARCH}

The results indicate that customers' concern about fairness of information management and their level of ethical idealism are positively associated with customers' demand that a policy of periodic information systems audit be used in the information management function of data driven organizations. Even though correlation does not necessarily imply causality, it can still be said that this finding can be a call for information policy makers, information system designers and administrators to implement information systems audits in the management of organizational information about customers, especially if customers tend to be ethically idealistic and their concern about fairness of data management is high. As individuals' concern about fairness of information management in organizations increases, organizations can adopt and implement IS audit policies to prevent abuses, errors and violations and build and maintain customers' trust, cooperation and patronage. This recommendation should be especially relevant and useful for organizations that depend on the patronage and cooperation of customers whose average ethical idealism score is high.

For future research, one could interview managers, system designers, policy makers, data managers, and database administrators to identify with greater detail what specific aspects of information management practices, policies and activities related to management of customer records need to be subjected to a policy of periodic information systems audit in order to reduce customers' concerns about fairness of information management in data-driven organizations. Instead of reacting to customers' concern about fairness, managers may also choose to be proactive in implementing information systems audit in order to to prevent tensions about fairness to build up in the first place. 


\begin{tabular}{|lrc|}
\multicolumn{2}{|c}{ Appendix A: Survey Questionnaire } \\
\hline Your Student status & 1. Graduate & 2. Undergraduate \\
\hline Your gender: 1. Male & 2. Female \\
\hline
\end{tabular}

The purpose of this survey is to analyze students' attitudes and opinions about information management functions at universities. The term IS stands for Information Systems. Please express your opinion about each statement presented to you by circling the number that best expresses your level of agreement with the statement.

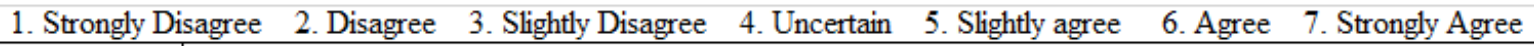

\begin{tabular}{|c|c|}
\hline 12344567 & $\begin{array}{l}\text { The IS problem definition should take into account, in a balanced way, the vital interests and competing } \\
\text { claims of all stakeholders who will be affected by the IS. }\end{array}$ \\
\hline 23345667 & $\begin{array}{l}\text { System designers and planners should make sure that interests of the information system's different } \\
\text { stakeholders have been justly considered and balanced. }\end{array}$ \\
\hline 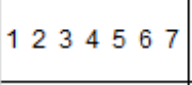 & $\begin{array}{l}\text { I believe that reports involving different stakeholders of a university should contain a balanced presentation of } \\
\text { the results. }\end{array}$ \\
\hline & I am concerned that reports \\
\hline
\end{tabular}

$\begin{array}{llllllll}1 & 2 & 3 & 4 & 5 & 6 & 7 & \text { A university should make certain that its actions related to students' personal information handling never }\end{array}$ intentionally harm a student even to a small degree.

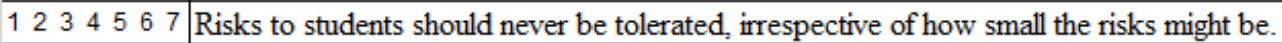

$\begin{array}{llllll}1 & 2 & 3 & 5 & 6 & 7\end{array}$ The existence of potential harm to others (e.g.students) is always wrong, irrespective of the benefits to be gained.

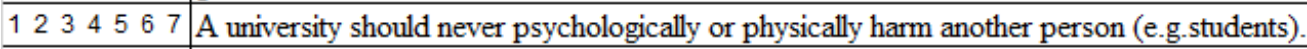

$\begin{array}{lllllllll}1 & 2 & 3 & 4 & 5 & 6 & 7 & \text { A university should not perform an action which might in any way threaten the dignity and welfare of another }\end{array}$ individual.

$\begin{array}{llllllll}1 & 2 & 3 & 4 & 5 & 6 & 7 & \text { If an action could harm an innocent other, then it should not be done. }\end{array}$

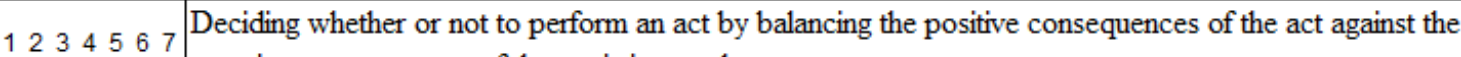
negative consequences of the act is immoral.

$\begin{array}{lllllll}1 & 2 & 3 & 4 & 5 & 6 & 7\end{array}$ The dignity and welfare of people (e.g. students) should be the most important concern of any university.

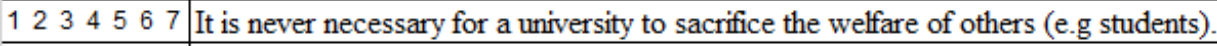

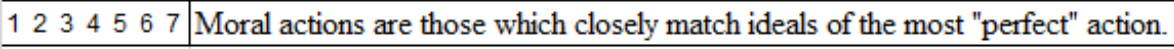

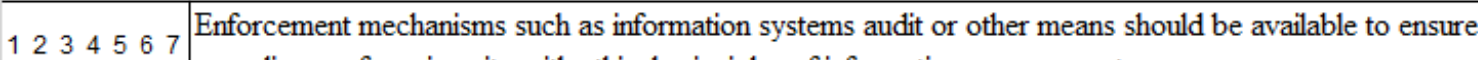
compliance of a university with ethical principles of information management.

Audits such as ethical checks of information should be conducted on a regular basis to ensure that any new

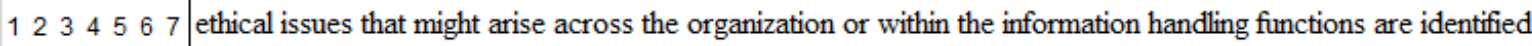
and dealt with.

\section{REFERENCES}

1. Barnard, C. I. (1938) The functions of the executive. Cambridge, M.A: Harvard University Press.

2. Cronbach, L. J. and Meehl, P.E. "Construct Validity in Psychological Tests," Psychological Bulletin (52:4), July, 1955, pp. 281-302.

3. Date, C.J. An Introduction to Database Systems (4th ed.), Addison-Wesley Publishing Company, Reading, MA, 1986.

4. Drucker, P.F. (1988, January-February). "The coming of the new organization." Harvard Business Review, pp.48-53

5. Forsyth D. R (1980). A taxonomy of ethical ideologies. J Pers Soc Psychol 1980;39(1):175- 84.

6. Forsyth D. R (1992). Judging the morality of business practices: the influence of personal moral philosophies. J Bus Ethics 1992;11:461-70.

7. Greenberg J. (1990). Organizational justice: Yesterday, today, and tomorrow. Journal of Management, 16, 399-432. 


\section{Issues in Information Systems \\ Volume 15, Issue II, pp. 197-206, 2014}

8. Hair, Joseph F. Jr. Anderson, Rolph E.Tatham, Ronald L and Black, William C. Multivariate Data Analysis (1998), fifth edition, Prentice Hall

9. Laudon, K.C. Dossier Society: Value Choices in the Design of National Information Systems, Columbia University Press, New York, 1986.

10. Mahmood, M.O.; Becker, Jack D.Effect of Organizational Maturity on End-Users' Satisfaction with Information Systems . Journal of Management Information Systems, Winter85/86, Vol. 2 Issue 3, p37, 28p;

11. Mason, R. O. "Four Ethical Issues of the Information Age," MIS Quarterly (10:1), March 1986, pp. 4-12.

12. Mason, Richard O. Mason, Florence M. Culnan, Mary J. Ethics of Information Management. Sage series in business ethics (SSBE). Sage Publications, 1995.

13. Miller, A. "Computers and Privacy," in Ethics and the Management of Computer Technology, W. M. Hoffman, and J. M. Moore (eds.), Oelgeschlager, Gunn, and Hain Publishers, Inc.,Cambridge, MA, 1982.

14. Mollick, J. S. (2006). Do Concerns about Error in Data and Access to Data Affect Students' Feeling of Alienation?. Journal of Information Privacy and Security, 2(1), 29-46.

15. Mollick, J. S. (2007). Do Concerns about Error and Profiling Correlate with Students' Demand for Formal Information Management Procedures at Universities? The Journal of Academic Administration in Higher Education, 3(1\&2), 33-42.

16. Mollick, J. S. (2008). How do Concerns about Organizational Fairness and Profiling Affect Individuals' Feeling of Alienation? Issues in information Systems (IIS), IX(2), 570-577.

17. Mollick, J. S. (2009). Ethical Idealism, Concern About Ethics of Information Management and Demand for Notice About Uses of Personal Information. The Business Review, Cambridge, 12(1), 54-59.

18. Mollick, J. S. (2009a). Concern about Fairness, Ethical Idealism and Demand for Formal Procedures of Information Management. Communications of the IIMA Journal, 9(1), 15-30.

19. Mollick, J. S. (2009b). Determinants of Perceived Customer-Centrism in Managing Information About Customers. Journal of American Academy of Business, 15(1), 9-15.

20. Mollick, J. S. (2010). How do Concerns about Access to Data and Fairness of Information Management Correlate with Demand for Notice about Uses of Personal Information? The Journal of Academic Administration in Higher Education, 6(1), 25-32.

21. Mollick, J. S., Pearson, J. M. (2006). Do Information Privacy Concerns Affect Students' Feeling of Alienation?. Journal of International Technology and Information Management, 15(1), 79-90.

22. Nolan, R.L. Managing the computer resource: a stage hypothesis. Communications of the ACM, 16, 7 (July 1973), 399-405.

23. Rawls, John. (1971) A Theory of Justice. Cambridge, Massachusetts: Belknap Press of Harvard University Press.

24. Simon, H. A. (1976). Administrative behavior (3rd ed.). New York: Mcmillan

25. Smith, H. J. Managing Privacy: Information Technology and Organizational America, University of North Carolina Press, Chapel Hill, NC, 1994.

26. Smith, H. Jeff; Milberg, Sandra J. "Information privacy: Measuring individuals' concerns about organizational practices." MIS Quarterly, June 1996, Vol 20(2) pp. 167-197.

27. Thompson, James D (1967). Organizations in action; social science bases of administrative theory; Published: New York, McGraw-Hill

28. Vitell SJ, Lumpkin JR, Rawwas MYA.(1991) Consumer ethics: an investigation of the ethical beliefs of elderly consumers. J Bus Ethics 1991;10: 365- 75.

29. Vitell SJ, Muncy J(1992). Consumer ethics: an empirical investigation of factors influencing ethical judgments of the final consumer. J Bus Ethics 1992;11:585- 97. 